\title{
The effect of light source distance on diametral tensile strength of nano particle composite
}

\author{
Renny Febrida*, Ellyza Herda**, Andi Soufyan** \\ *Department of Dental Material Science \& Technology Faculty of Dentistry Universitas Padjadjaran \\ **Department of Dental Material Science Faculty of Dentistry Universitas Indonesia
}

\section{ABSTRACT}

The use of nano particle composite in posterior region is somehow difficult due to the limited space to place the light source as close as possible to the restorative material. The distance between the light source and restorative material surface leads to decreased light intensity that causing inadequate polymerization. The inadequate polymerization affects the composite diametral tensile strength. Two types of nano particle composite, i.e. Filtek ${ }^{T M} \mathrm{Z}-350$ and Ceram- $X^{T M}$ were tested for their diametral tensile strength, which is affected by the distance of the light source from the composite material surface. Some cylindrical specimens were exposed to light with various distances from the light source, i.e. $0,1,2,3,4$, and $5 \mathrm{~mm}$ from the specimen surface. From the six distance variations tested the diametral tensile strength of Filtek Z-350 is $64.09-58.20 \mathrm{MPa}$ with the significant result in 2, 3, 4 and 5 $\mathrm{mm}$ distances; and the diametral strenght of Ceram- $X$ is $47.52-42.20 \mathrm{MPa}$ with the significant result in 2 , 3,4 and $5 \mathrm{~mm}$ distances. The results of this study show that the increased distance of the light source from the nano particle composite restorative material leads to decreased diametral strength of the two nano particle composites tested.

Key words: Nano particle composite, light source distance, diametral tensile strength

\section{INTRODUCTION}

The use of resin composite as restorative materials in posterior teeth has several limitation such as the difficulty to place the light source as close as possible (tight contact) with resin composite material. Toget optimum polymerization from light activated composite materials, the resin composite material and the light source should be in tight contact and the thickness of resin composite should not be more than $2 \mathrm{~mm} .^{1-3}$ If there is any distance between the light source and composite material, the intensity of the light received by composite material will be less than the light intensity at the light source. Adequate light with precise wavelength range should reach the whole resin composite material that is activated by the light to get optimum polymerization ${ }^{3,4}$ and the long term clinical success. ${ }^{3}$

The distance between the light source and composite material will make polymerization of the resin composite imperfect which directly causes decreased mechanical properties of the resin composite materials such as reducing the strength of the resin composite material. Because the light-activated resin composite material 
depends very much on the accurate light intensity with tight contact between the light source and resin composite material surface, those are necessary for optimum polymerization. ${ }^{3}$ Besides, with a distance between the light source and the resin composite material, the depth of the light penetration becomes limited and this leads to light scattering on the resin composite material. ${ }^{5}$

The light penetration depth is directly affected by filler particle size of resin composite. The light scattering in resin composite material increases due to the filler particle size that is similar to the wavelength of the light source that will reduce light transmission in the composite material. $^{3}$ In addition to the filler side, the shape and amount of filler also affect the light penetration depth in polymerization that will affect the physical, mechanical and biological nature of the composite. The inadequate polymerization will reduce hardness, strength and color stability and will increase water absorption. ${ }^{6}$ The best light penetration depth is at the restoration thickness of $1-2 \mathrm{~mm} .{ }^{7,8}$

Several studies on the effect of light source distance from the resin composite surface have been performed by several researchers, such as the one performed by Pires et al. ${ }^{9}$ on the effect of light source distance from the micro filler composite material surface to the upper and lower surface hardness of the microfiller composite material. The result of this study shows that increased distance between the light source and resin composite material surface will cause reduced hardness, especially the hardness of the lower surface of the composite material. ${ }^{9}$ Furthermore, Koupis et al. ${ }^{10}$ suggested that the hardness ratio of the lower surface to the upper surface reflects the relative curing degree of the resin composite material. A study by Sobrinho et al. ${ }^{3}$ on the effect of light source distance with resin composite material to the surface hardness of microfiller composite also show similar result with the study done by Pires et al. ${ }^{9}$

According to Neo et al. ${ }^{11}$ the maximum distance between the light source and resin composite material surface is $4 \mathrm{~mm}$ with a material thickness of $2 \mathrm{~mm}$. Powers et al. ${ }^{12}$ suggested a maximum distance between the light source and the composite material of $1 \mathrm{~mm}$ with 2-2.6 $\mathrm{mm}$ thickness to get optimum polymerization. ${ }^{16}$
Ferracane $^{2}$ suggested that if it is possible the light source and the resin composite material should be in tight contact to get optimum polymerization. If it is not possible to place the light source in tight contact with resin composite material, the maximum distance between the light source and the composite material is $1-2 \mathrm{~mm}$.

Recently, a resin composite material with a very small filler particle has been developed, i.e. composite with nanometer scale filler particle $(0.1$ $100 \mathrm{~nm}$ ) called nanocomposite. The nanocomposite materials can be used as restorative materials in anterior and posterior teeth due to the fact that it is a combination of two composite types, i.e. hybrid composite with adequate strength for posterior restoration (high stress bearing area) and macrofiller composite for restoration in anterior teeth with better esthetics. ${ }^{13}$

From several studies performed, there has not been any study on the effect of the light source distance to the nano particle composite strength. Therefore, a research on the effect of the light source distance to the diametral tensile strength of the nano particle composite is necessary. The Nano particle composite can be used for restorative material in posterior teeth although the application is difficult clinically because it is difficult to place the light source as close as possible or in a tight contact with composite material surface.

\section{MATERIALS AND METHODS}

Two types of nano particle composite were used for this study, i.e. Filtek ${ }^{T M}$ Z-350 and Ceram$X^{T M}$, with a composition shown in Table 1 . The total number of samples of the two nano particle composite products was 120 , each product was represented by 60 specimens. Ten specimens were placed in each distance group. The light distance used were $0,1,2,3,4$, and $5 \mathrm{~mm}$ from the composite material surface. The diametral tensile strength test specimens were cylindrical with a diameter of $6 \mathrm{~mm}$ and a thickness of 3 $\mathrm{mm} 3 \mathrm{~mm}$ (ADA specification no. 27) ${ }^{14}$ and was made using metal splitmold. The specimens were exposed to light produced by Litex LED curing light instruments 20 second. Each time the specimen is exposed by the light, the light intensity produced by the light source was calibrated using Litex LED 
Table 1. Composition of two nano particle composite product.

\begin{tabular}{|c|c|c|c|c|}
\hline Material & Matric & Filler & Color & Manufacturer \\
\hline \multirow{4}{*}{ Filtek Z-350 } & Bis GMA, Bis EMA, & Nanosilika filler $20 \mathrm{~nm}$ & A3 & \multirow{4}{*}{$\begin{array}{l}3 \text { M ESPE } \\
\text { Jerman }\end{array}$} \\
\hline & UDMA, and a little & Aglomerat Zr/Si 5-20 nm & & \\
\hline & bit TEDGMA & Cluster $\mathrm{Zr} / \mathrm{Si}$ 0,6-1,4 $\mu \mathrm{m}$ & & \\
\hline & & Volume filter: $78,5 \%$ & & \\
\hline \multirow[b]{2}{*}{ Ceram-X } & Dimethacrylate, resin, & Barium-Aluminium-Borosilicate glass $\sim 1 \mu \mathrm{m}$ & A3 & \multirow[b]{2}{*}{$\begin{array}{l}\text { Dentsply } \\
\text { USA }\end{array}$} \\
\hline & $\begin{array}{l}\text { Methacrylate modified } \\
\text { polysiloxane }\end{array}$ & $\begin{array}{l}\text { Nanofilter } \sim 10 \mathrm{~nm} \\
\text { Methacrylate functionalized silicon dioxide } \\
2-3 \mathrm{~nm} \\
\text { Volume filler: } 79,5 \%\end{array}$ & & \\
\hline
\end{tabular}

TGA test result up to $500^{\circ} \mathrm{C}$

Radiometer. One hour after the exposure, the specimen was removed from the mold. It was then washed using soft detergent and rinsed by water. The specimen was then kept in a plastic vial containing of $2 \mathrm{ml}$ of aquadest and placed into an incubator with a temperature of $37^{\circ} \mathrm{C}$ ( $\pm 1^{\circ} \mathrm{C}$ ) for 24 hours. After 24 hours, the diametral tensile strength was measured using universal testing machine. Specimen is loaded by $250 \mathrm{kgf}$ continually with a speed of $1 \mathrm{~mm} /$ minute until fracture occurred. The data collected were then analyzed using two way ANAVA.

\section{RESULTS}

The diametral tensile strength of the two tested nano particle composite type, i.e. Filtek Z-350 and Ceram-X is listed in Tab. 2 and Graphic 1. The statistical analysis using Anava test on Filtek Z-350 and Ceram-X composites show that there is an effect of the light source distance to the composite diametral tensile strength. Based on Tukey advance test for Filtek Z-350 composite, a light source distance of $2,3,4$, and $5 \mathrm{~mm}$ from the composite material surface produces significantly different result for $\alpha=0.05$ in terms of composite diametral tensile strength. For Ceram- $\mathrm{X}$ composite, it is significantly different for $a=0.05$ when the light source is $2,3,4$, and $5 \mathrm{~mm}$ from the composite material in terms of composite diametral tensile strength.

Based on the surface analysis using SEM with a magnification of 500X, it is seen that the filler particle distribution on the two nanoparticle composites is very even (Fig. 1). The surface seems to be smoother for Filtek Z-350 composite. The analysis on the fracture point using SEM with 2000x magnification shows a fracture pattern of brittle fracture (Fig. 2).

\section{DISCUSSION}

The diametral tensile strength for the two nano particle composite studied decreases when there is increased distance between the light source with the composite surface. The average range of the diametral tensile strength for Filtek Z-350 composite is $64.09 \mathrm{MPa}$ to $58.19 \mathrm{MPa}$, while for Ceram-X composite the range is $47.51 \mathrm{MPa}$ to $42,21 \mathrm{MPa}$ at the six light source distances in this study. The diametral tensile strength for hybrid composite is $42 \mathrm{MPa} .{ }^{1}$ While according to ADA specification no. 27 year 1977, the diametral tensile strength for resin composite is $34 \mathrm{MPa} .{ }^{14}$ The SEM test results for the two composites show a similar feature, i.e. brittle fracture appearance (Fig. 2A and B).

The difference in the strength of the two nano particle composite type may be due to the difference in the composition of the two composite types, both in resin matrix and filler composition. A higher strength found in Filtek Z-350 composite compared to Ceram- $X$ is especially caused by different fillers. The silica/zirconium filler in Filtek Z-350 composite increases the strength of the composite materials compared to the silicon dioxide and barium-aluminum-borosilicate glass filler in Ceram- $X$ because silica/zirconium filler has a higher molecular weight and density compared to barium-aluminum-borosilicate glass. ${ }^{15}$ Although the silica/zirconium nanocluster filler particle absorbed more light, the resin matrix used in Filtek Z-350 composite, i.e. BisEMA and UDMA, can diffuse visible light better in the composite materials. Furthermore, the sylanization process in Filtek Z-350 composite is done through 2 methods, 
Padjadjaran Journal of Dentistry 2008;20(3):149-54.

Table 2. Diametral tensile strength/DTS average and standard deviation of Filtek Z-350 and Ceram-X (MPa) composite.

\begin{tabular}{ccc}
\hline \multirow{2}{*}{$\begin{array}{c}\text { Exposure Distance } \\
(\mathrm{mm})\end{array}$} & \multicolumn{2}{c}{ Average diametral strength/DTS \pm SD $(\mathrm{Mpa})$} \\
\cline { 2 - 3 } & Filtek Z-350 & Ceram-X \\
\hline 0 & $64.091 \pm 1.07$ & $47.52 \pm 0.42$ \\
1 & $64.08 \pm 0.95$ & $46.79 \pm 0.76$ \\
2 & $63.69 \pm 0.89^{* *}$ & $46.47 \pm 0.81 * *$ \\
3 & $61.73 \pm 1.12^{* *}$ & $46.13 \pm 0.87^{* *}$ \\
4 & $58.75 \pm 1.27^{* *}$ & $43.91 \pm 0.61 * *$ \\
5 & $58.20 \pm 1.44^{* *}$ & $42.2 \pm 1.26^{* *}$ \\
\hline & &
\end{tabular}

Graphic 1. Comparison of diametral tensile strength average of Filtek Z-350 and Ceram-X composites based on the distance from light source.

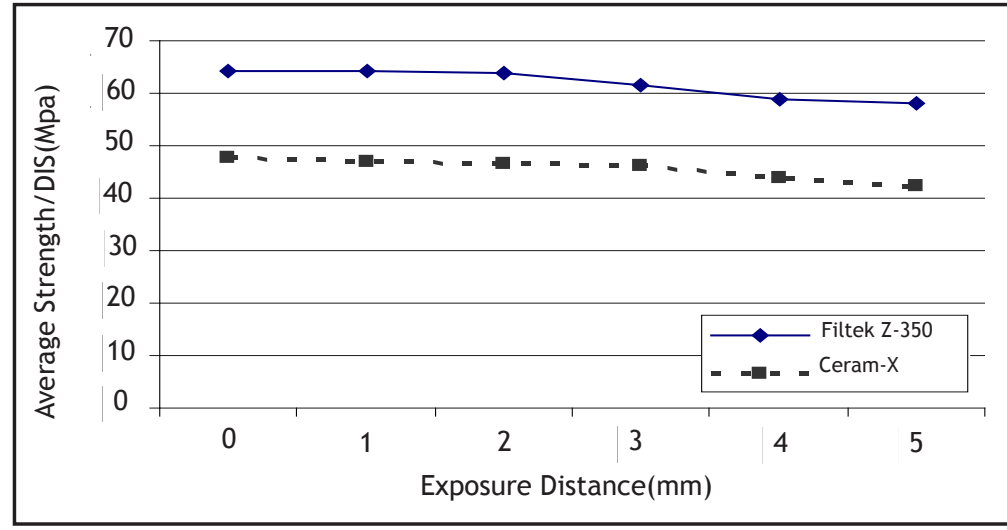

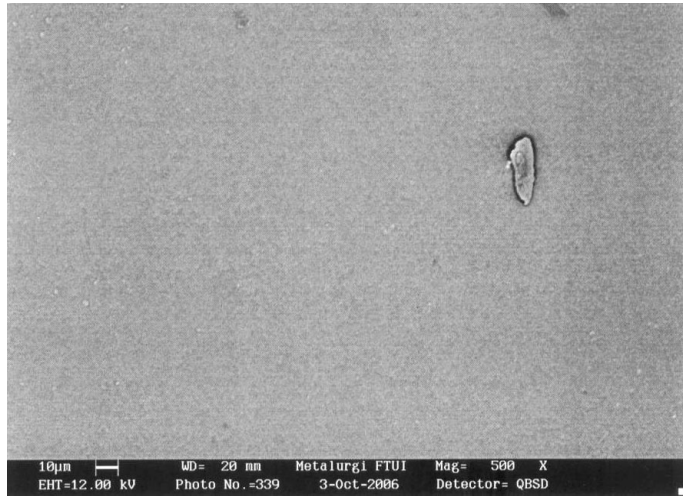

A

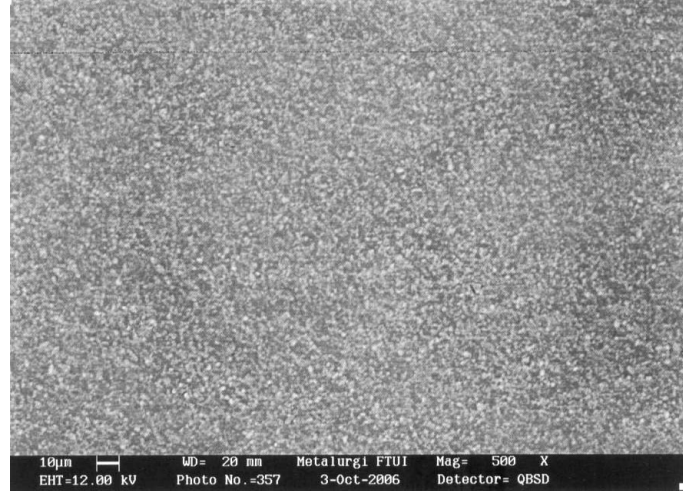

Figure 3. A. FiltekZ-350 surface, magnification 500x, B. Ceram-X surface, magnification 500x.

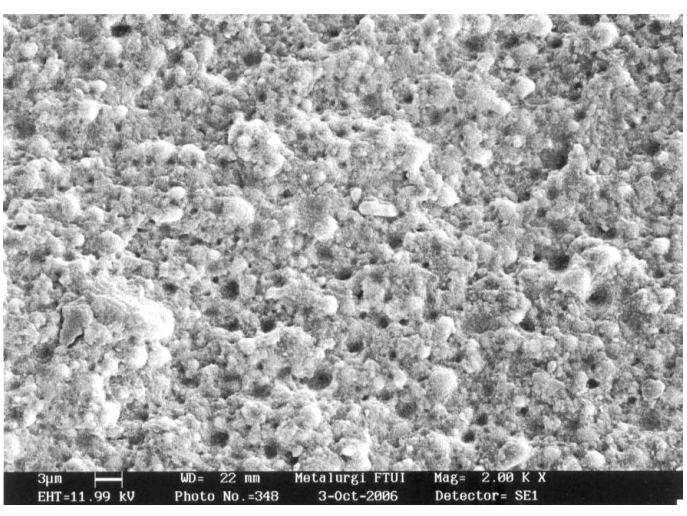

A

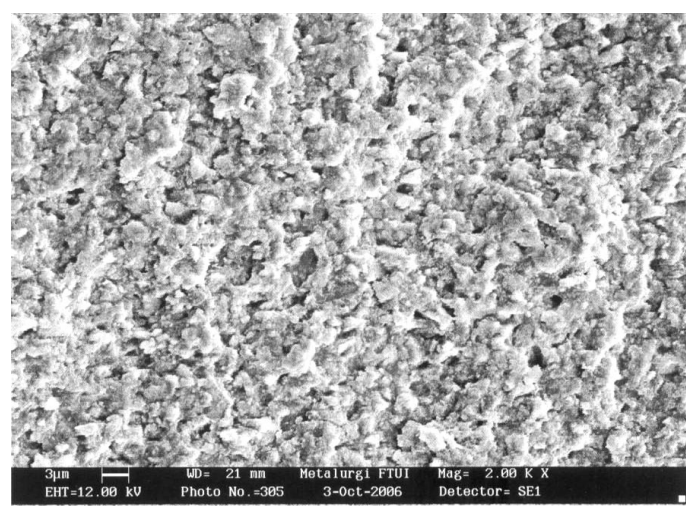

B

Figure 4. A. Filtek Z-350 fracture magnification 2000x, B. Ceram-X fracture magnification 2000x. 
sylanization of nanomeric silica filler particle and sylanization of nanocluster silica/zirconium particle that can improve its strength compared to Ceram-X. Sylanization betweeen filler particle and composite matrix may affect the composite material strength. ${ }^{15}$

The difference in resin composite matrix of the two composite also affect the strength of the composite material. Filtek Z-350 composite contains BisEMA, UDMA and some TEGDMA. BisEMA and UDMA have a high molecular weight with good properties for visible light diffusion. BisEMA is a hydrophobic monomer and is able to maintain the bond between filler particles with resin matrix.

Meanwhile, UDMAcan improve the toughness of the resin matrix. The diametral strength that is higher compared to this Filtek Z-350 composite is related to the ability of UDMA to make hydrogen bound in co-polymer producing sliding border of the polymer segment. ${ }^{18}$

The color used for the two composites are A3 with a thickness of $3 \mathrm{~mm}$ which may also cause decrease light penetration depth in the composite material. Darker color such as A3 and a thickness of more than $2 \mathrm{~mm}$ needs longer exposure to light to get a total energy that will enable the composite materials to polymerize the deepest part of the material. Furthermore, with the increased light source distance, a weaken light intensity will be received by the composite material.

The exposure time used in this study is 20 seconds, which is the same as the exposure time instructed by the manufacturer of the light source. The light source used was LED with an early light intensity at the tip of the instrument of $1,120 \mathrm{mWatt} / \mathrm{cm}^{2}$. According to Peris et al. ${ }^{17}$ an exposure time of 20 seconds using LED is adequate for composite material polymerization because LED has a specific pattern in the light emission which is similar to the absorption spectrum of comporquinone as the photoactivator of the resin composite material. According to Sobrinho et al. ${ }^{3}$ the polymerization depth is closely related to the thickness of the materials and light intensity provided. The weakening of the light intensity received by the resin composite material due to the distance between the light source and the resin composite material can be compensated by increasing the exposure time.

\section{CONCLUSION}

The strength of the two tested nanoparticle composite type is reduced with the presence of distance between the light source and composite materials. The decreased strength is significant for the distance of 2, 3, 4, and 5 of the composite material surface, both for nanotparticle composite Filtek Z-350 and Ceram-X while for the distance of $1 \mathrm{~mm}$, there is no significant strength reduction compared to $0 \mathrm{~mm}$ distance both for both for nanotparticle composite Filtek Z-350 and Ceram$\mathrm{x}$.

\section{REFERENCES}

1. Bayne SC, Thompson JY, Taylor DF. Dental materials. In: Roberson TM, Heymann HO, Swift EJ, editors. Art \& science of operative dentistry. $4^{\text {th }}$ ed. St. Louis: Mosby Inc.; 2002. p. 136-41,190-207.

2. Ferracane JL. Materials in dentistry. Principles and applications. $2^{\text {nd }}$ ed. Philadelphia: Lippincott Williams \& Wilkins; 2001. p. 98101.

3. Sobrinho LC, delima AA, Consani S, Sinhoreti MAC, Knowles JC. Influence of curing tip distance on composite Knoop hardness values. J Brazilian Dent 2000;11(1):11-7.

4. Park SH, Krejci I, Lutz F. Microhardness of resin composites polymerized by plasma arc or conventional visible light curing. J Operative Dentistry 2002;27:30-7.

5. Coffey O, Ray NJ, Lynch CD, Burke FM, Hannigan A. In vitro study of surface microhardness of a resin composite exposed to a quartz-halogen lamp. J Quintessence Int 2004;35(10):795800.

6. Herrero AA, Yaman P, Dennison JB. Polymerization shrinkage and depth of cure of packable composites. J Quintessence Int 2005;36(1):25-31.

7. St-Georges AJ, Swift Jr EJ, Thompson JY, Heymann HO. liradiance effects on the mechanical properties of universal hybrid and flowable hybrid resin composites. J Dent Mater 2003;19:406-13.

8. Poskus LT, Placido E, Cardoso PEC. Influence of placement techniques on Vickers and 
Knoop hardness of class II composite resin restorations. J Dent Mater 2004;20:726-32.

9. Pires JAF, Cvitko E, Denehy GE, Swift EJ Jr. Effects of curing tip distance on light intensity and composite resin microhardness. J Quintessence Int 1993;24(7):517-21.

10. Koupis NS, Martens LC, Verbeeck RMH. Relative curing degree of polyacid-modified and conventional resin composites determined by surface Knoop hardness. J Dent Mater 2006;22:1045-50.

11. Neo JCL, Yap AUJ. Composite resins. Preservation and restoration of tooth structure. In: Mount GJ, Hume WR, editors. Queensland Australia: Knowlegde books and software multimedia; 2005. p. 201-7.

12. Powers JM, Sakaguchi RL. Restorative dental materials. $12^{\text {th }}$ ed. St. Louis: Mosby Inc.; 2006: 64-5, 79-82, 190-200, 202-3.

13. Mitra SB, Wu D, Holmes BN. An application of nanotechnology in advanced dental materials. JADA 2003;134:1382-90.

14. Council on Dental Materials and Devices. New American Dental Association Specification No. 27 for direct filling resins. JADA 1977;94:11915.

15. Uctasli S, Tezvergil A, Lassila LVJ, Vallittu PK. The degree of conversion of fiber-reinforced composites polymerized using different lightcuring sources. J Dent Mater 2005;21:469-75.

16. Tolosa MCCGT, Paulillo LAMS, Giannini M, dos Santos AJS, Dias CTS. Influence of composite restorative materials and light-curing units on diametrical tensile strength. J Brazilian Dent 2005;19(2):1-7.

17. Peris $A R$, Mitsui FHO, Amaral CM, Ambrosano GMB, Pimenta LAF. The effect of composite type on microhardness when using quartztungsten-halogen (QTH) or LED lights. J Operative Dentistry 2005;30(5):649-54. 